\title{
Application of Mathematical Modeling in Marketing Management Problem
}

\author{
Xuemei YU \\ Beijing Polytechnic \\ Beijing, 100176
}

\begin{abstract}
The enterprise should develop the production and sales plan with maximum profit, double profit and balanced sales as goals according to external demand and internal conditions. They should also apply linear programming, integer programming, multi-objective programming model in operational research model, double profit, multiple modeling ideas, hierarchical analysis, and combine Lindo, Lingo, Excel, Matlab and other mathematical software to analyze and collate data, so as to achieve the production and marketing optimization.
\end{abstract}

Keywords-Mathematical Modeling; Marketing Management; Optimization; Balanced Sales

\section{INTRODUCTION}

Marketing strategy determines the development direction and significant action steps of the enterprise and directly affects the enterprise's survival and development. The products produced by average enterprises should be sold through the Marketing Department. As the production capacity of an enterprise is limited, the production shall be selectively arranged on the potential contracted amount on the basis of meeting the signed sales contract quantity. On the one hand, the enterprise will organize and arrange production and complete the signed sales contract; On the other hand, the enterprise expects the Marketing Department to try its best to sign the formal sales contract with the potential customers; In addition, the enterprise wants the Sales Department to try to sell more unplanned products.

For the sales contract signed and the planned potential contracted amount, the enterprise shall pay the salary, publicity expenses and other expenditures to the Marketing Department according to the sales volume; For the unplanned products sold, the contract system is implemented, and the Marketing Department pays the profits to the enterprise. The production cost of the products shall be borne by the enterprise, and the expenses related to sales shall be borne by the Marketing Department [1]. How to make a production and marketing plan becomes an important part.

A company plans to produce three categories of 10 small household appliances in 2017, including: Kettle (1.5 L, 1.8 L, 2 L), soybean milk machine $(0.9 \mathrm{~L}, 1.1 \mathrm{~L}, 1.3 \mathrm{~L})$, rice cooker $(2$ L, 2.5 L, $3 \mathrm{~L}, 3.5 \mathrm{~L})$. The maximum annual production capacity of three categories of household appliances is: Kettle: 50,000; Soybean milk machine: 65,000 pieces; Rice cooker: 62,000 Detailed data includes: "Signed contracted quantity" and "potential contracted volume" of 10 small household appliances [2]; Production cost of the company; The publicity expenses of each category of small household appliances change with the sales volume; The sales amount of each product changes with the order quantity of each contract; Signing amount of 8 orders signed by the company; Potential contracted amount of five potential customers; The probability of each potential signed customer to sign the order contract; The probability of signing the order contract for unplanned products sold by the Marketing Department; For the planned products sold, the expenditure (RMB ten thousand) issued by the enterprise to the Marketing Department; For the unplanned part sold, the profit (RMB ten thousand) paid by the Marketing Department to the enterprise [1].

The goal is to develop corresponding production and sales plans for the company according to the following requirements:

(1) Maximize the company's profits;

(2) Maximize the general income of the Marketing Department;

(3) Give consideration to the interests of both the company and the Marketing Department [2].

\section{PROBLEM ANALYSIS}

First, the goal of this optimization problem is to make different production and sales plans under different requirements. The decision to be made is the production plan and sales plan, that is, how many appliances are produced respectively for three categories of 10 small household appliances, and how many appliances need to be sold in addition to planned appliances and the decision is limited by multiple conditions: Signed contracted quantity, potential contracted amount, cost of production, publicity expenses of every small home appliance with the change of sales volume, sales amount of each product with the change of contract order quantity, probability of occurrence of the planned potential contracted amount, probability of unplanned order contracted quantity sold by the Sales Department, the expenditure issued by the enterprise to the Marketing Department because of the planned products sold and unplanned profit paid by the Marketing Department to the enterprise.

Secondly, there are many complex decision variables and there is a certain functional relation between various constraint conditions. We can see from the relationship given in the data table that there is a certain linear relationship between production capacity and cost, sales amount and order quantity, the expenditure of the planned products sold issued by the enterprise to the Marketing Department and planned sales volume and they can be expressed by the linear function. 
Finally, to maximize the corporate profit, it refers to the situation where the sum of planned sales profit and unplanned profit paid to the enterprise by the Marketing Department is optimized. This belongs to double profit and is made by using multiple modeling methods. To maximize the general income of the Marketing Department, it refers to how to arrange the sales plan of the Marketing Department on the basis of the planned sales contract and the potential contracted amount. The general income of the Marketing Department shall be determined jointly by the expenditure issued to the Marketing Department by the enterprise according to the planned sales volume, and the unplanned profit paid to the enterprise by the Marketing Department and unplanned expenses related to sales; Multiple modeling places extra emphasis on the Marketing Department's general income maximization. For the purpose of giving consideration to the interests of both the company and the Marketing Department, the dynamic programming model is first used to realize the maximum profit, and then the analytic hierarchy process is used for allocation and management, so as to meet the requirements. The sales need to be balanced in order to meet the interests of the company and the Marketing Department as well as the customers' needs, that is, in addition to the planned signed sales contract, the potential contracted amount and the expected profit of unplanned sales profit need to be obtained, so as to give consideration to all three. In addition to the planned products sold, it is necessary to generate more profits from the perspective of the sales department, and to maximize the general income of the Marketing Department, that is, when the general income of the Marketing Department is the maximal, more profits are also created for the company.

\section{MODEL ASSUMPTION}

A complete marketing management plan consists of two parts. The first part is production, including raw material cost, production technology and other factors. Only after taking into account the constraints of various factors affecting production can the enterprise make correct analysis in this stage. The second part is sales, which aims to obtain ideal profits and where there are also many intangible constraints, such as the sales publicity cost, consumer purchasing psychology. Because of the complexity and diversity of economic phenomena, it isn't realistic to model after all the influencing factors are considered. Therefore, it is necessary to make some practical theoretical assumptions for the multi objective programming approach in the production marketing, so as to reduce the uncertainty in the model and make the model operable. Furthermore, it is assumed that there are no other factors affecting the decision variables except the constraint conditions in the problem. The symbols are described as follows for the convenience of model building and problem solving.

$i$ : Label the kettle, soybean milk machine and electric cooker according to their models from 1 to 10 , namely $i=1,2,3,4,5,6,7,8,9,10$;

$x_{i}$ : Production quantity of the ith of 10 small household appliances; $m_{i}$ : Production cost of the ith of 10 small household appliances;

$y_{i}$ : Sales volume of the ith small household appliance;

$n_{i}$ : Publicity expenses of the ith small household appliance;

$z_{j i}:$ Order quantity of the ith small household appliance in the jth contract;

$p_{j i}$ : Sales amount of the ith small household appliance in the jth contract;

$a_{i}$ : Planned sales volume of the ith small household appliance;

$q_{i}$ : Planned expenditure issued by the enterprise to the Marketing Department according to the sales volume of the ith small household appliance;

$b_{i}$ : Unplanned quantity of the ith small household appliance sold by the Marketing Department;

$k_{i}$ : Unplanned profits paid by the Marketing Department to the enterprise after the sales of the ith product;

$E_{k}(i)$ : Expectation of the ith small household appliance in the order contract signed by the potential consumer $k$, $k=1,2,3,4,5$.

\section{MODEL BUILDING}

A. Objective function: Profit A obtained by the company; General income B of the Marketing Department

(1) The relational expression between the trend figure and parameters is formed by using Excel and the production capacity $x_{i}$ of the ith small household appliance and the cost $m_{i}$ used to produce this appliance satisfy a functional relation [3]: $m_{i}=F\left(x_{i}\right)$;

(2) The relational expression between the trend figure and parameters is formed by using Excel and the publicity expenses $n_{i}$ of the ith small household appliances and the sales volume $y_{i}$ of this product satisfy a certain functional relation: $n_{i}=G\left(y_{i}\right)$;

(3) The relational expression between the trend figure and parameters is formed by using Excel and there is a certain function relationship between the sales amount $p_{j i}$ of the ith small household appliance in the jth contract and the order quantity $z_{j i}$ of the appliance in the contract: $p_{j i}=H_{i}\left(z_{j i}\right)$;

(4) There is a certain linear relationship between the sales volume $a_{i}$ of the ith small household appliance and the amount of expenditure $q_{i}$ issued to the Marketing Department 
by the enteprises according to the sales volume of the ith small household appliance in the plan and the and the relational expression between the trend figure and parameters is formed by using Excel: $q_{i}=O_{i}\left(a_{i}\right)$.

(5) There is a linear relationship between the profit $k_{i}$ paid by the Marketing Department to the enterprise after selling the ith product and the quantity $b_{i}$ of the ith small household appliances sold by the Marketing Department beyond the plan and the function relationship between the two is deduced: $k_{i}=I_{i}\left(b_{i}\right)$

(6) The characteristics of description of random variables can be solved by expectation. As the signing volume of various products is random, we choose the plan with the maximum expected order quantity according to the principle of maximum order quantity generated by the expectation, so as to achieve balanced sales and give consideration to the interests of the company and Marketing Department as well as the needs of customers.

\section{B. Constraint conditions}

(1) Production capacity: xi is measured in ten thousand; the maximum annual production capacity of three categories of small household appliances is: Kettle: 50000; Soybean milk machine: 65000 ; 62000 rice cookers, namely

$$
\left\{\begin{array}{l}
x_{1}+x_{2}+x_{3} \leq 5 \\
x_{4}+x_{5}+x_{6} \leq 6.5 \\
x_{7}+x_{8}+x_{9} \leq 6.2
\end{array}\right.
$$

(2) Known planned contracted amount:

$x_{1} \geq 0.8, \quad x_{2} \geq 2.0, \quad x_{3} \geq 1.0, \quad x_{4} \geq 1.0, \quad x_{5} \geq 2.0$, $x_{6} \geq 1.5, x_{7} \geq 1.1, x_{8} \geq 1.7, x_{9} \geq 1.0, x_{10} \geq 0.5$.

(3) The planned order quantity is less than or equal to the sales volume and the sales volume is less than or equal to the production capacity: $z_{j i}<y_{i}<x_{i}$.

(4) Corporate profit:

$A=\sum_{i=1}^{10} \sum_{j=1}^{8} p_{j i}+\sum_{i=1}^{10} \sum_{k=1}^{5} p_{k i}+\sum_{i=1}^{10} k_{i}-\sum_{i=1}^{10} m_{i}-\sum_{i=1}^{10} q_{i}$.

(5) General income of the Marketing Department:

$$
B=\sum_{i=1}^{10} q_{i}+\sum_{i=1}^{10} p_{i}-\sum_{i=1}^{10} n_{i}-\sum_{i=1}^{10} k_{i}-\sum_{i=1}^{10} m_{i} .
$$

To sum up, we can obtain

$$
\begin{aligned}
& \operatorname{Max} A=\sum_{i=1}^{10} \sum_{j=1}^{8} H_{i}\left(\mathrm{z}_{j i}\right)++\sum_{i=1}^{10} I_{i}\left(b_{i}\right)-\sum_{i=1}^{10} F_{i}\left(a_{i}\right)-\sum_{i=1}^{10} O_{i}\left(a_{i}\right), \\
& \operatorname{Max} B=\sum_{i=1}^{10} O_{i}\left(a_{i}\right)+\sum_{i=1}^{10} H_{i}\left(\mathrm{z}_{i}\right)+\sum_{i=1}^{10} G_{i}\left(y_{i}\right)-\sum_{i=1}^{10} I_{i}\left(b_{i}\right)-\sum_{i=1}^{10} F_{i}\left(a_{i}\right) .
\end{aligned}
$$

\section{V.MODEL SOLUTION}

The trend figure 1 of the relationship between 10 small household appliances and the cost in the following table can be obtained by using Excel according to the data fitting:

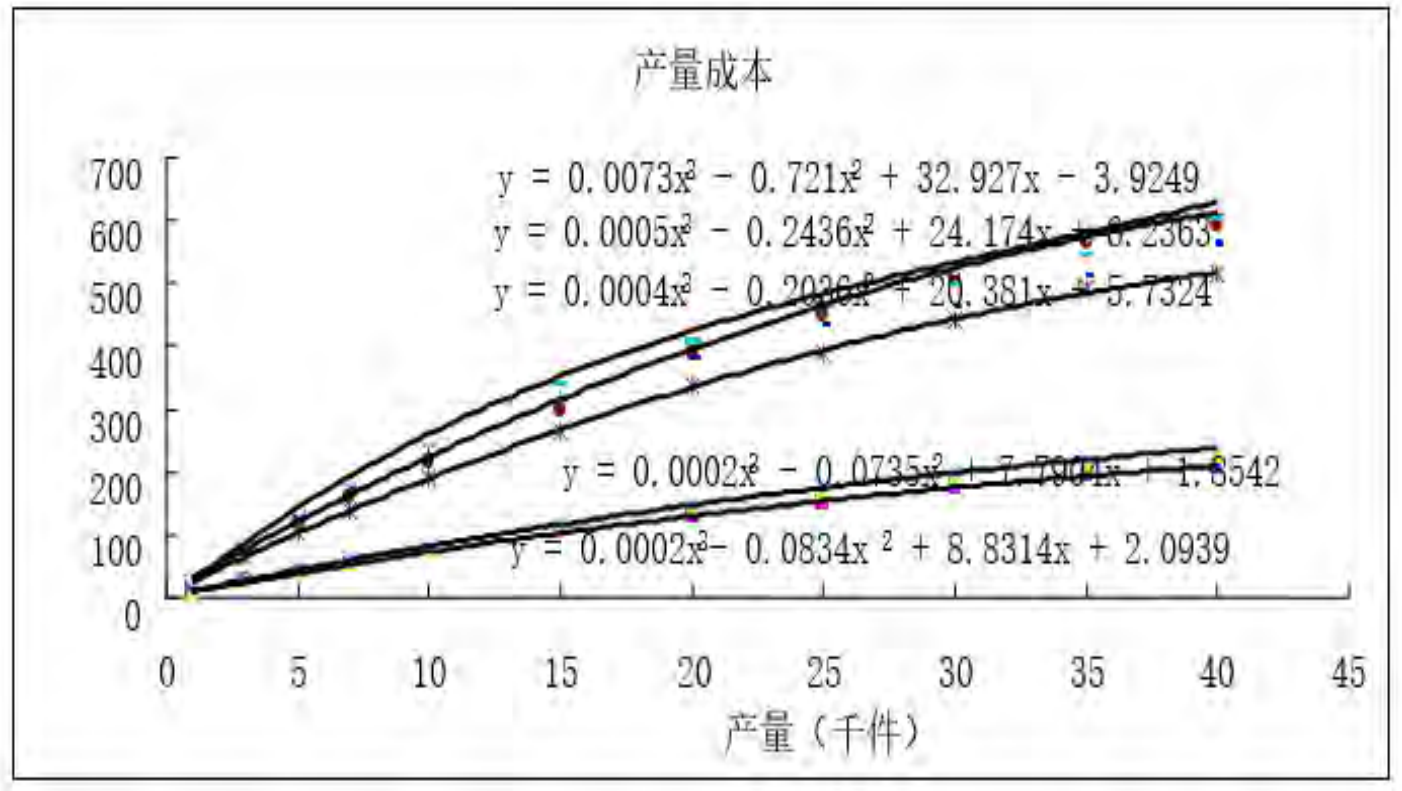

Fig. 1 The relationship between output and cost

The trend figure 2 of the relationship between publicity expenses and sales volume of 10 small household appliances in the following table can be obtained by using Excel according to the data: 


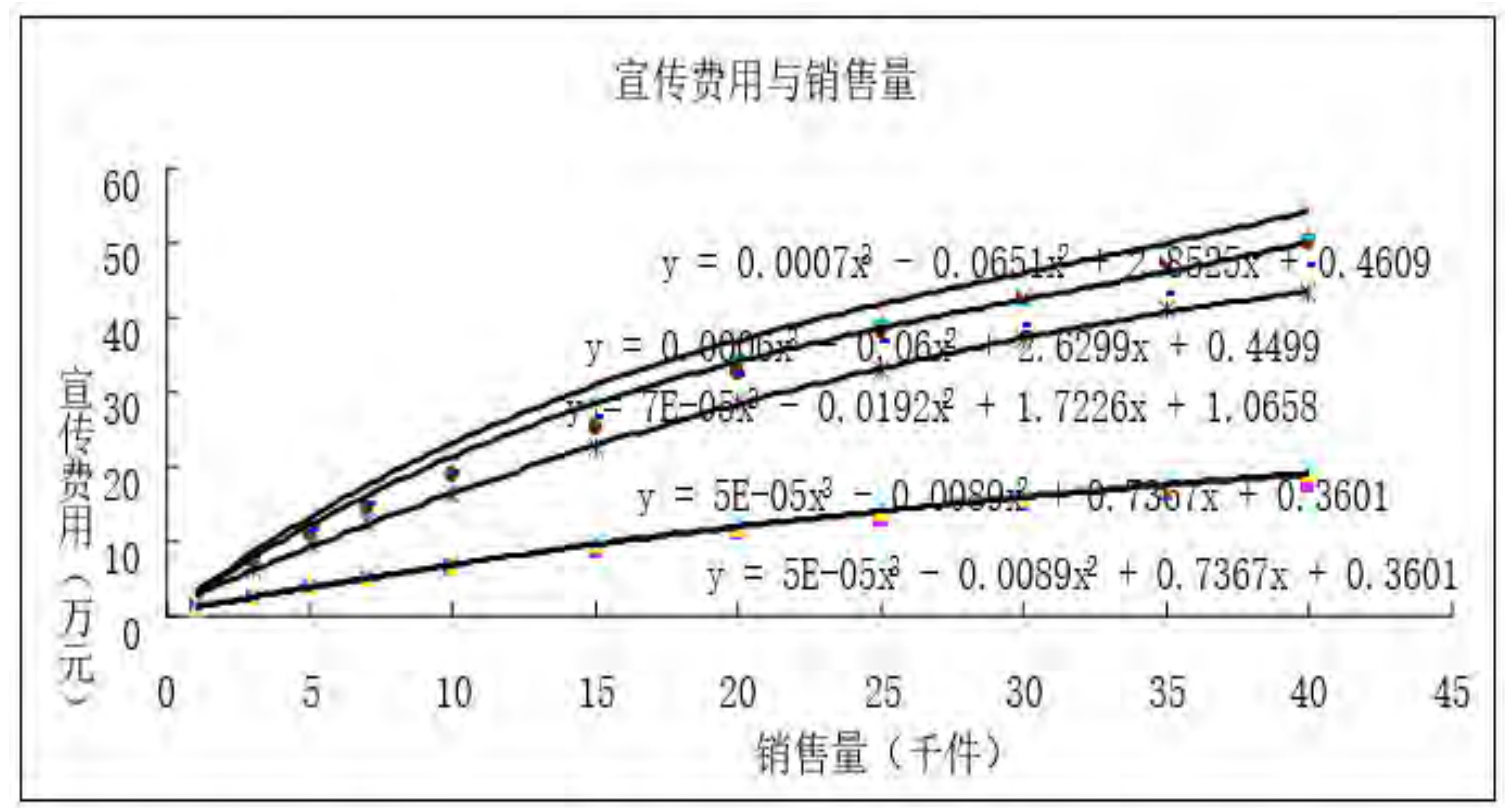

Fig. 2 The relationship between publicity expenses and sales volume.

The trend figure 3 of the sales amount of 10 small household appliances with the change of the order quantity can be obtained by using Excel according to the data:

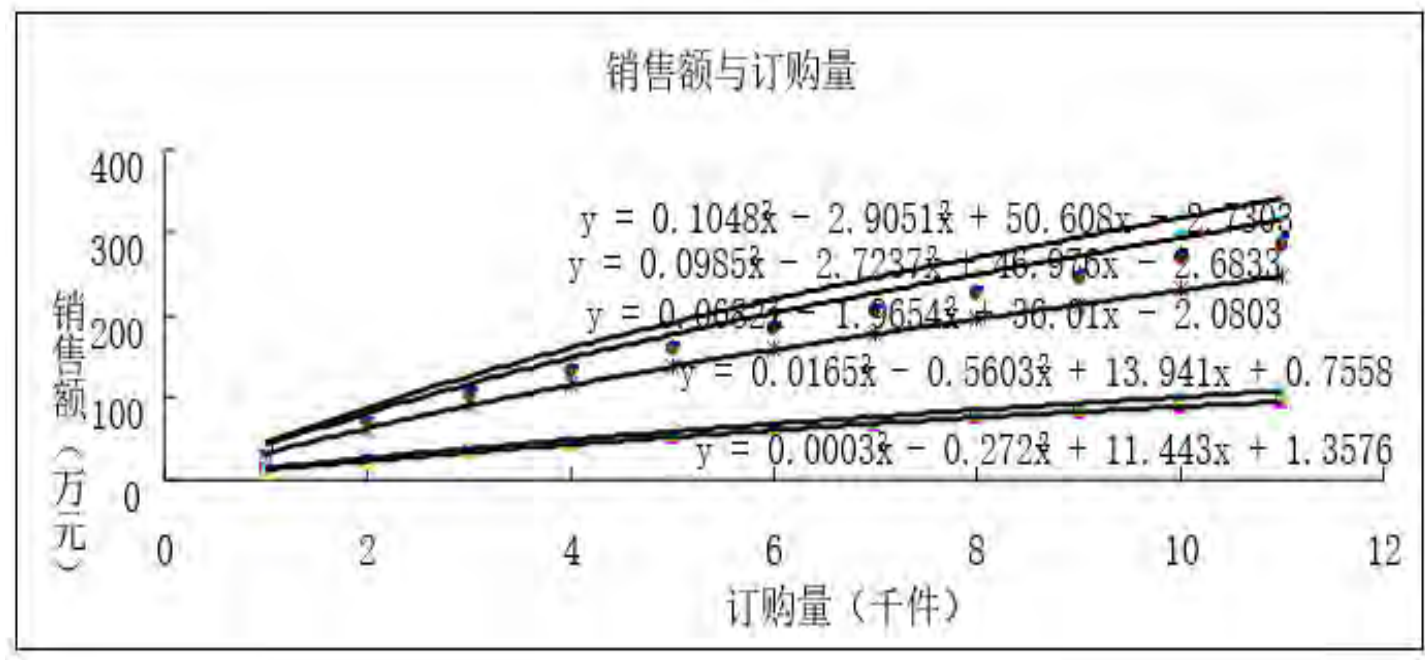

Fig. 3 The relationship between sales amount and order quantity.

The trend figure 4 of the relationship between the planned expenditure issued to the Marketing Department by the enterprise and the product sales volume can be obtained by using Excel according to the data: 


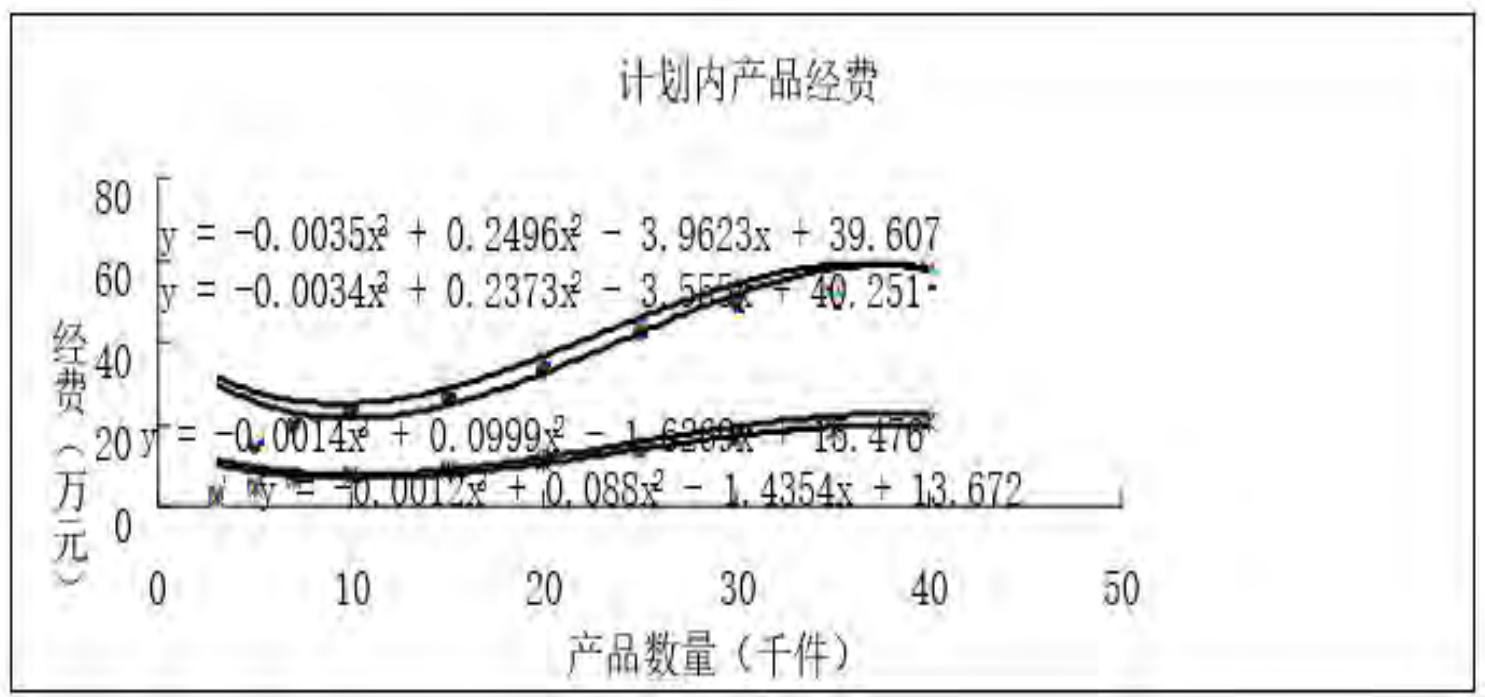

Fig. 4 The relationship between planned expenditure and product sales volume.

The trend figure 5 of the unplanned profits from sales of 10 small household appliances paid to the enterprise by the Sales
Department with the change of sales volume can be obtained by using Excel according to the data fitting:

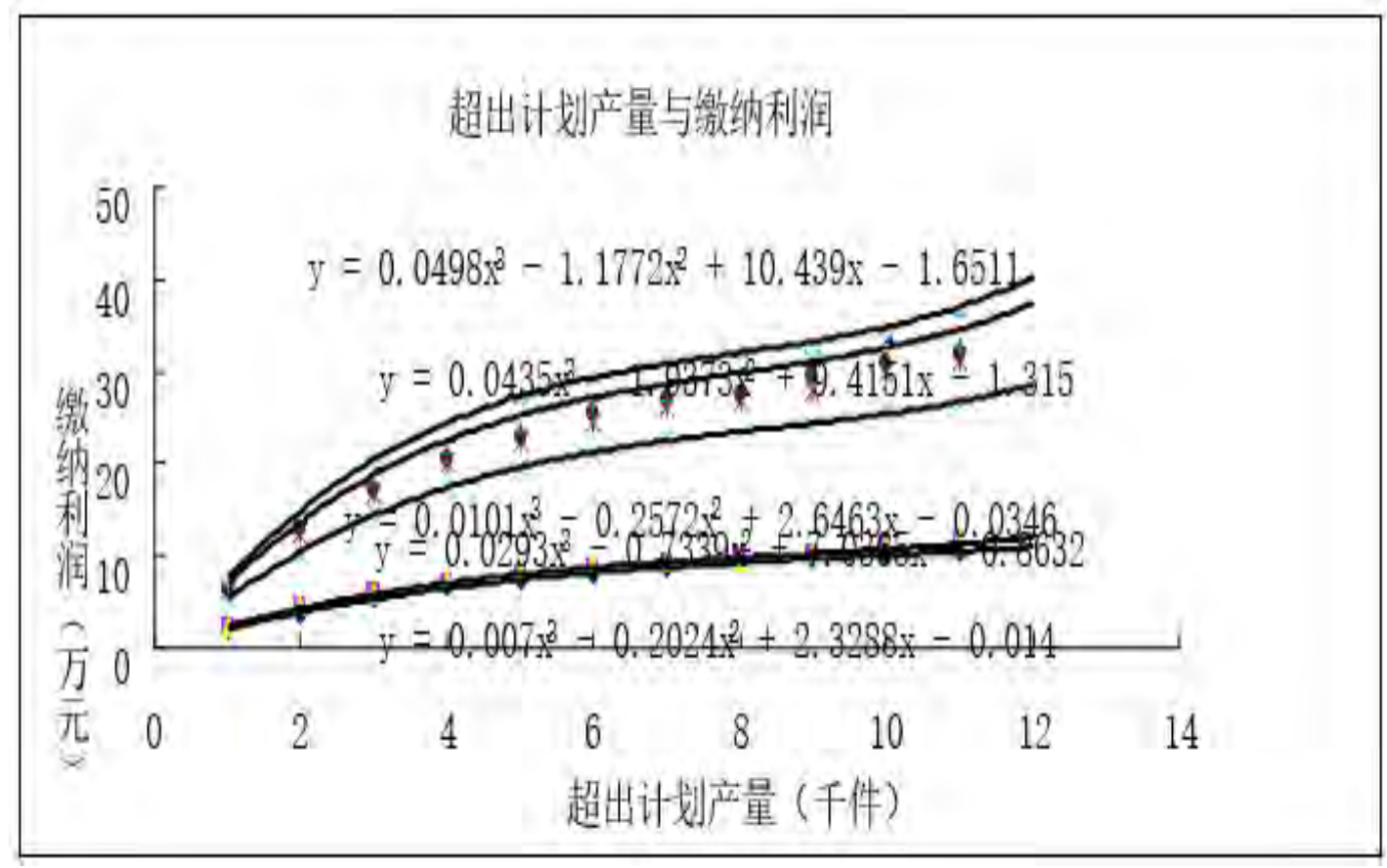

Fig. 5 The relationship between profits and unplanned sales volume.

(1) It can be seen from Figure 1 that to maximize $A$, the planned signed contract is fixed, the sales amount of each category of small product can be calculated according to Figure 3 ; To get the greater profit, the planned potential contracted amount must be obviously completed, otherwise it is classified to unplanned part; For the unit products, the corporate profit is far less than the planned nominal sales income. We take the first product as an example, the cost of production is $m_{1}=F\left(x_{1}\right)$, the signed amount is 8000 , the potential contracted amount is 3000 , the order quantity of No. 1 product in 8 orders is 4500 and 3500 respectively and the sum of sales is $p_{11}+p_{31}=H_{1}(0.45)+H_{1}(0.35)$;

In addtion, assuming that the potential contracted amount is completed, the sales amount is $\sum_{i=1}^{5} p_{i}=2 H_{1}(0.15)$,

The planned total sales amount of No. 1 product is $H_{1}(0.45)+H_{1}(0.35)+2 H_{1}(0.15)$. 
The planned total amount of No.1 product sold is 11000 , and the expenditure provided to the Sales Department is $q_{1}=O_{1}(1.1)$; The unplanned amount of No.1 products sold is $\left(x_{1}-11000\right)$ and the profit paid by the Sales Department is $k_{1}=I_{1}\left(x_{1}-1.1\right)$, so obtain,

$$
\begin{gathered}
A_{1}=H_{1}(0.45)+H_{1}(0.35)+2 H_{1}(0.15), \\
+I_{1}\left(x_{1}-1.1\right)-O_{1}(1.1)-F_{1}(1.1),
\end{gathered}
$$

Compare the above procedures and obtain $A_{i}$, $1.5 \geq x_{1} \geq 1.1$; In the same way, obtain $2.4 \geq x_{2} \geq 2.3$, $1.6 \geq x_{3} \geq 1.2$. It can be assumed that the optimal solution will be obtained at a certain point in the feasible region determined by the constraint conditions, and the theory of linear programming can prove that our conjecture is correct. The profit paid to the enterprise by the Marketing Department for selling one unit of product is less than the profit gained by the enterprise for selling one unit of product in the plan. We can directly observe the conclusion from the data and the fitting trend figure. If the enterprise wants to make a big profit, it should try its best to achieve all the success in the plan. Analyze the unplanned sales profit obtained by the company. The decision of unplanned production also directly affects the gross profit of the enterprise. Take $x_{1}, x_{2}$ and $x_{3}$ as an example, the relationship between profits paid to the enterprise under the unit sales volume is $k_{1} \leq k_{2} \leq k_{3}$, the Sales Department only sells the unplanned third category of products in order to obtain the larger profits. Based on the above analysis, make the production plan $x_{1}=1.1, x_{2}=2.3, x_{3}=1.6$, $x_{4}=1.5, x_{5}=2.5, x_{6}=2.5, x_{7}=1.3, x_{8}=2.7, x_{9}=1.3, x_{10}=0.9$.

The sales plan strictly implements the planned sales, so that the indefinite potential signing is successful. We can get MaxA $=571.6861626$ by using mathematical software and at this time $\sum_{i=1}^{10} I_{i}\left(b_{i}\right)=0$.

(2) General income $B$ of the Marketing Department: To maximize the general income of the Marketing Department, we can imagine that the expenditure required for the planned production capacity is fixed. Assuming that the potential contracted amount isn't successful, all produced goods are sold by the Marketing Department in the unplanned name, the income of the Marketing Department can be maximized under such condition. It's very easy for us to figure out from the trend figure that the sales amount of some product is far greater than the publicity expenses and the profit paid to the enterprise by the Marketing Department because of selling some product is less than the difference between the sales amount and cost of the product, so we can set the plan boldly: $x_{1}=0.8, x_{2}=2.0$, $x_{3}=2.2, x_{4}=1.0, x_{5}=2.0, x_{6}=3.5, x_{7}=1.1, x_{8}=1.7, x_{9}=1.0$, $x_{10}=2.4$. All the planned potential contracted amount isn't completed, all products are sold by the Marketing Department, only a close margin of profit is handed over to the enterprise, so the general income of the Marketing Department is very high at this point. We can gain $\operatorname{MaxB}=178.69321$.
(3) To sum up two plans, to make the interests of the company and Marketing Department equal, in addition to the signed order in the plan, whether the potential contracted amount is completed isn't absolute, that is, ai of the production capacity xi of each product is the planned sales volume and the product quantity in the signed contract must be known; bi is the unplanned volume sold by the Marketing Department, regard the planned products sold as a whole, make it simple and idealized and assume at this point:

$$
\begin{aligned}
& A_{i}=H_{i}\left(a_{i}\right)+I_{i}\left(b_{i}\right)-F_{i}\left(a_{i}\right)-O_{i}\left(a_{i}\right), \\
& B_{i}=H_{i}\left(b_{i}\right)-I_{i}\left(b_{i}\right)-F_{i}\left(b_{i}\right)-G_{i}\left(x_{i}\right)+O_{i}\left(a_{i}\right) .
\end{aligned} .
$$

$A_{i}$ and $B_{i}$ are mutually restrictive. The interests $A$ of the company and the general income $B$ of the Marketing Department are equivalent as long as the difference between the profit $A_{i}$ of each product brought to the company and the income $B_{i}$ brought to the Marketing Department is minimal, that is,

$$
\begin{aligned}
\operatorname{Min}\left|A_{i}-B_{i}\right| & =H_{i}\left(a_{i}\right)-F_{i}\left(a_{i}\right)-2 O_{i}\left(a_{i}\right) \\
& +2 I_{i}\left(b_{i}\right)-H_{i}\left(b_{i}\right)+F_{i}\left(b_{i}\right)+G_{i} F_{i}\left(x_{i}\right)
\end{aligned}
$$

Make a comprehensive image based on the data Matlab and find out a point $Q\left(a_{i}, b_{i}\right)$ from the image, making the distance from this point to $A_{i}$ and $B_{i}$ equal, and then obtain the optimal plan to achieve the profit $A$ of the company and general income $B$ interests of the Marketing Department equal.

\section{CONCULSION}

The expected goal developed in the enterprise production management and decision-making isn't unique, and it isn't appropriate to use linear programming to determine the use of resources and allocation of elements in production. The common method to solve this problem is the goal-planning method. The goal programming is to use multiple goals instead of single goal to seek optimization, which corresponds to reality and has application value. The enterprise optimal production plan problem is not only the problem of allocating the existing resources of the enterprise in multiple production tasks according to the principle of maximum benefit or minimum cost, but also the problem of making the production tasks of the enterprise satisfy the maximum market demand through reasonable organization of resources [3].

\section{REFERENCE}

[1] Marketing Management Problems of an Enterprise, http://wenku.baidu.com/view/f9092e0102020740be1e9b29.html.

[2] Analysis of Marketing Management Problems of Mathematical Modeling Enterprises,http://download.csdn.net/source/2318542.

[3] Yan ZHANG, Ting WEI, Xuan HU. Marketing Management Problems of an Enterprise [J]. Natural science journal of Harbin Normal University, 2010, 26 (5): 30-31.

[4] Huawen TANG, Mingfeng HE. Mathematical Modeling [M]. Beijing: Higher Education Press, March 2005.

[5] QingyanHAN, Enterprise Sales Profit Optimization Model based on Nonlinear Programming [J]. Value project, 2013, 33: 138-139.

[6] Zhecheng AN, Guangying YU. Development of Company Production and Sales Plan based on Genetic Algorithm [J].Journal of Shenyang Ligong University, 2011, 30 (3):88-89. 